\title{
SMART SfM: SALINAS ARCHAEOLOGICAL MUSEUM
}

\author{
L. Inzerillo ${ }^{a *}$ \\ a DARCH, Department of Architecture, Polytechnic School, 90128 Palermo, Italy - laura.inzerillo@unipa.it
}

KEY WORDS: SfM, Image Based Modelling, Photogrammetry, 3D model, Archaeological museum

\begin{abstract}
:
In these last years, there has been an increasing use of the Structure from Motion (SfM) techniques applied to Cultural Heritage. The accessibility of SfM software can be especially advantageous to users in non-technical fields or to those with limited resources. Thanks to SfM using, everyone can make with a digital camera a 3D model applied to an object of both Cultural Heritage, and physically Environment, and work arts, etc. One very interesting and useful application can be envisioned into museum collection digitalization.

In the last years, a social experiment has been conducted involving young generation to live a social museum using their own camera to take pictures and videos. Students of university of Catania and Palermo were involved into a national event \#digitalinvasion (2015-2016 editions) offering their personal contribution: they realized 3D models of the museums collection through the SfM techniques. In particular at the National Archaeological Museum Salinas in Palermo, it has been conducted an organized survey to recognize the most important part of the archaeological collection. It was a success: in both \#digitalinvasion National Event 2015 and 2016 the young students of Engineering classes carried out, with Photoscan Agisoft, more than one hundred 3D models some of which realized by phone camera and some other by reflex camera and some other with compact camera too. The director of the museum has been very impressed from these results and now we are going to collaborate at a National project to use the young generation crowdsourcing to realize a semi-automated monitoring system at Salinas Archaeological Museum.
\end{abstract}

\section{INTRODUCTION}

\subsection{Introduction}

Low-cost digital photogrammetry using structure-from-motion (SfM) has made it possible for nearly anyone with a digital camera to create dense and precise point cloud models of the physical environment. (Inzerillo, L. et al, 2016).

Thanks to SfM using, everyone can make with a digital camera a 3D model applied to an object of both Cultural Heritage, and physically Environment, and work arts, etc. (Kersten, et al. 2012; Smith, et.al. 2015) .Photogrammetry describes a broad array of techniques used to derive physical measurements from 2D images, and digital photogrammetry describes any type of photogrammetry involving digital images (Verhoeven, 2011; Westoby, et al. 2012). Structure from motion (SfM) represents a popular photogrammetric method that uses the principle of parallax to derive 3D measurements based on shifts in image features from different photographs taken at different vantage points. (Mikhail, Bethel, \& McGlone, 2001).

The first step involved performing automatic image alignment to roughly align the images and place their respective "cameras" in space. As part of the alignment process, the software also made a first attempt to estimate camera lens characteristics. If successful, the initial image alignment step placed some or all images into their correct locations and generated a sparse point cloud of tie points - i.e., points representing key features detected in multiple images - that vaguely resembled the modeled scene.

Upon reaching a satisfactory state, the camera parameters can be calibrated one final time to optimize their parameters based on the refined image locations.
With all images correctly placed, the third step used SfM to generate a dense point cloud of coordinates based on information in the images. At this point, the resulting point cloud contained millions of points that collectively provided a photorealistic 3D rendering of the modeled object. The point cloud could be used as-is for measurement and visualization purposes or further processed for other purposes. However, using point clouds for visualization can result in pixelated images, which can be more pronounced in areas with sparser point densities. (Moussa, W.,M. et al. 2012)

Generating a textured mesh of the point cloud can remedy the point cloud pixilation problem and provide a photo-realistic 3D model of the mapped object. In the PhotoScan workflow, these last two steps involved generating a meshed surface based on the point cloud and then applying image-based texture -i.e., texture mapping - to the mesh for photorealism. (Kyriakaki, G., 2015)

Just as it is said, the SfM procedure is at the reach of everyone and for this reason, I proposed to the international event of the \#digitalinvasions, (Bonacini, E.,et al. 2014) to realize, for the first time, a $3 D$ \#digitalinvasion involving the Engineering Course students of the University of Palermo. The initiative was conducted for two years: in 2015 and 2016 at the Archaeological Salinas Museum in Palermo. (Fig. 1, 2)

First year engineering students were instructed on using of SfM techniques in a meeting at the museum one hour before the inauguration of the event.

the choice to do a lecture / tutorial has been taken to ensure student learning a new technique, just as if they followed a tutorial and then all apply the methodology.

\footnotetext{
* Corresponding author
} 


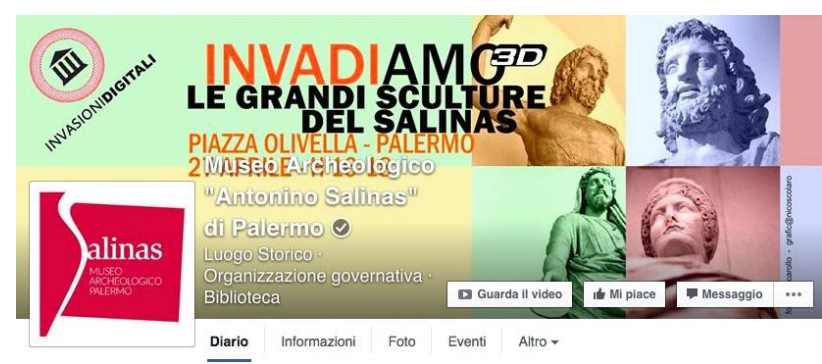

Figure 1. The social event of the 3D\#digitalinvasion

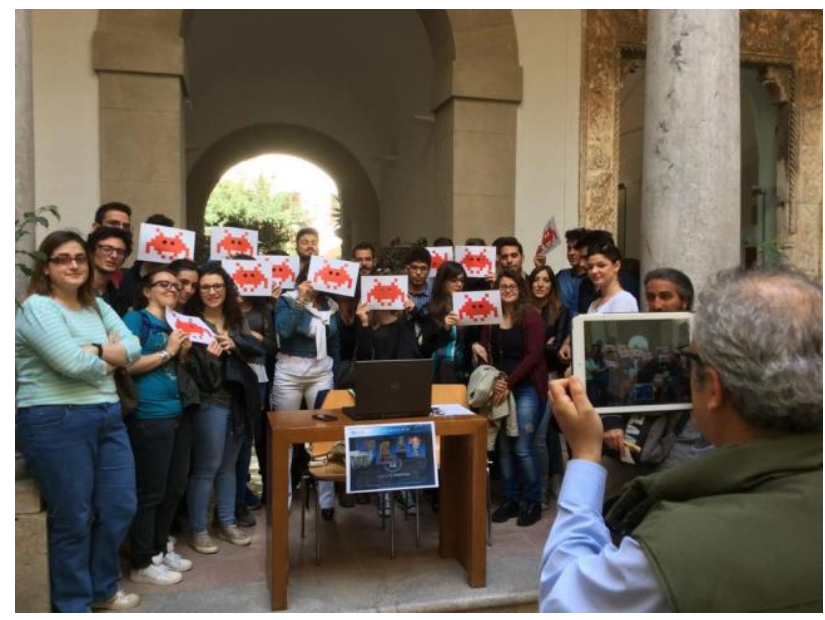

Figure 2. The students at the inauguration of the $3 D \#$ digitalinvasion

The experiment was a success that exceeded expectations. And these are some of the results (Fig. 3):

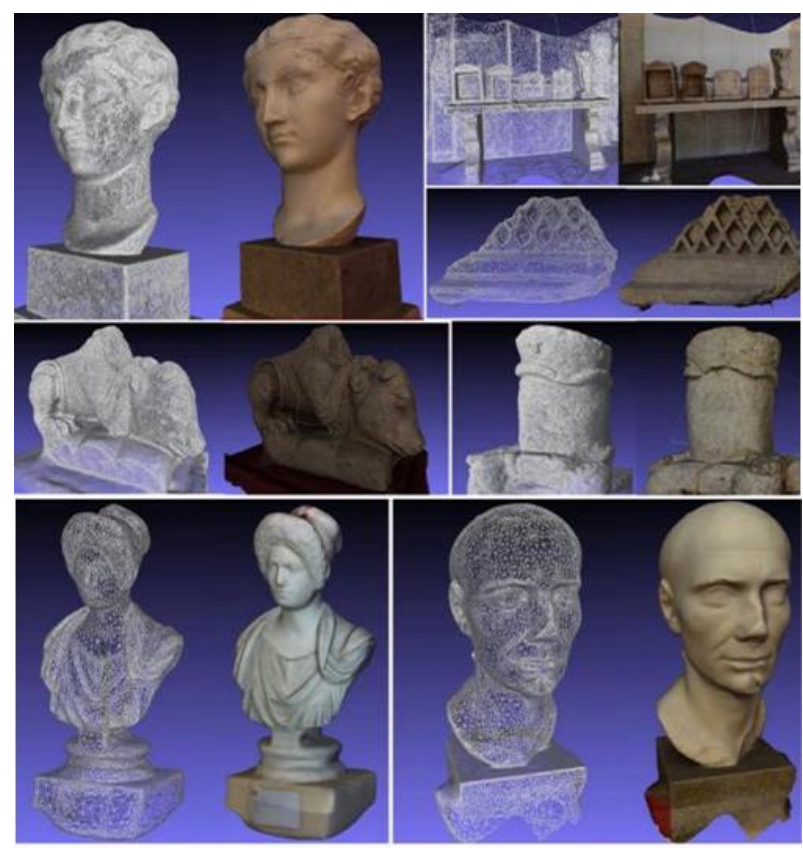

Figure 3. The results of the $3 D \#$ digitalinvasion

Precisely from these results comes the idea of the smart SfM. This idea is focused to use the crowdsourcing resources to make a planning of the monitoring of the museum collection.
In this paper you will find the workflow to realize this idea that has become a project.

\section{CROWDSOURCING}

2.1 The crowd sourcing aimed at a 3D repository of a museum collection

The crowdsourcing is the practice of obtaining needed services, ideas, or content by soliciting contributions from a large group of people and especially from the online community rather than from traditional employees or suppliers (Alsadik, B. 2016).

Crowdsourcing is a specific sourcing model in which individuals or organizations use contributions from users to obtain needed services or ideas. Crowdsourcing was coined in 2005 as a portmanteau of crowd and outsourcing.

This mode of sourcing, which is to divide work between participants to achieve a cumulative result, was already successful prior to the digital age (i.e., "offline"). Crowdsourcing is distinguished from outsourcing in that the work can come from an undefined public (instead of being commissioned from a specific, named group) and in that crowdsourcing includes a mix of bottom-up and top-down processes (Biella, D., 2015). Advantages of using crowdsourcing may include improved costs, speed, quality, flexibility, scalability, or diversity. Crowdsourcing in the form of idea competitions or innovation contests provides a way for organizations to learn beyond what their "base of minds" of employees provides. Crowdsourcing can also involve rather tedious "microtasks" that are performed in parallel by large, paid crowds. Crowdsourcing has also been used for noncommercial work and to develop common goods.

Knowledge discovery and management is used for information management problems where an organization mobilizes a crowd to find and assemble information. It is ideal for creating collective resources. (Howe, J. 2014)

Distributed human intelligence tasking is used for information management problems where an organization has a set of information in hand and mobilizes a crowd to process or analyze the information. It is ideal for processing large data sets that computers cannot easily do. (Vincent, M. L., et al. 2015) Broadcast search is used for ideation problems where an organization mobilizes a crowd to come up with a solution to a problem that has an objective, provable right answer. It is ideal for scientific problem solving.

Peer-vetted creative production is used for ideation problems, where an organization mobilizes a crowd to come up with a solution to a problem, which has an answer that is subjective or dependent on public support. It is ideal for design, aesthetic, or policy problems.

Crowdsourcing often allows participants to rank each other's contributions, e.g. in answer to the question "What is one thing we can do to make Acme a great company?" One common method for ranking is "like" counting, where the contribution with the most likes ranks first. This method is simple and easy to understand, but it privileges early contributions, which have more time to accumulate likes. (Stathopoilou, et al. 2015)

Some examples of successful crowdsourcing themes are problems that bug people, things that make people feel good about themselves, projects that tap into niche knowledge of proud experts, subjects that people find sympathetic or any form of injustice. (Oomen, J., et al. 2011)

In recent years, international projects have been funded on the use of crowdsourcing aimed at creating 3D models applied to 
civil and urban context and museum too (https://www.voorjebuurt.nl/about/?gclid=CjwKEAjw9_jJBRC XycSarr3csWcSJABthk07w_LBYJ_63rmSimjcerkB1FEXfeSh Tjg3fhgYD6xD8xoC1BXw_wcB).

But there is not any project that addresses the challenge of creating a workflow aimed at the realization of the $3 \mathrm{D}$ museum collection. The idea is to combine the potential of crowdsourcing with SfM techniques. (Fig. 4)

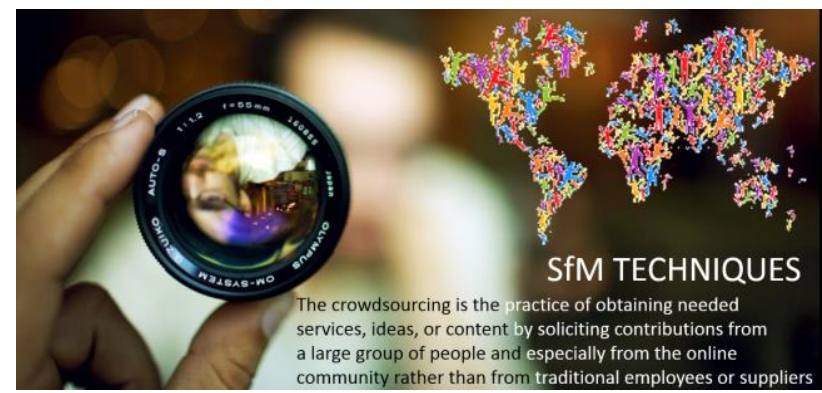

Figure 4. Crowdsourcing and SfM techniques

The most delicate phase in the launch of crowdsourcing initiative is the promotion: the promoter must make a real promotional campaign of the initiative using all communication systems that exist, social etc.

It must be an action of dissemination of the idea. (Fig 5)

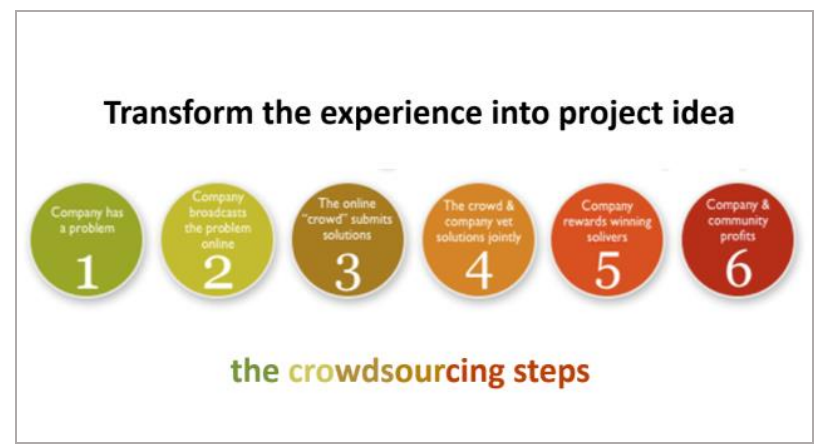

Figure 5. The crowdsourcing steps

In our case, step 3 does not materialize on line, but directly to the museum. Let's see "How"!

\section{WORKFLOW}

\subsection{The experiences of 2015 and 2016}

Before I started with 2015 3D\#digitalinvasion, I asked the museum to study the collection to divide it into categories. (Fig. 6) The categorization was a phase due to optimize student resources in a single event. Furthermore, in this first experiment, it was necessary to choose only a part of the collection: the most easily accessible, that was that one in the outdoor atrium, in order to detect any accidents within the indoor paths. (Guidi, G. et al. 2015)

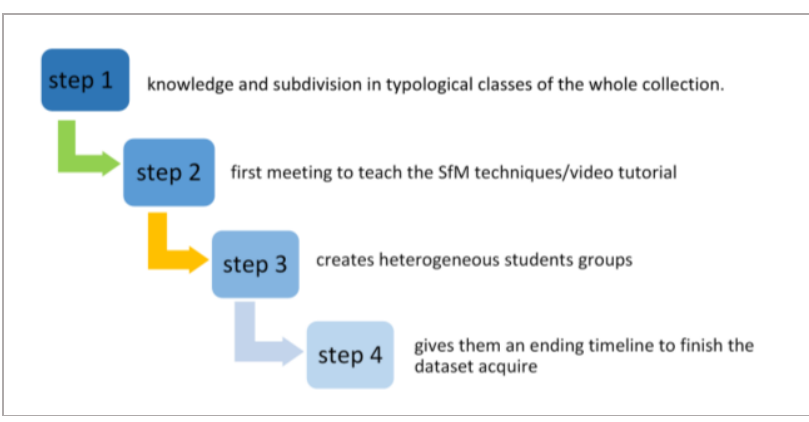

Figure 6. Methodology used in 2015 and 2016

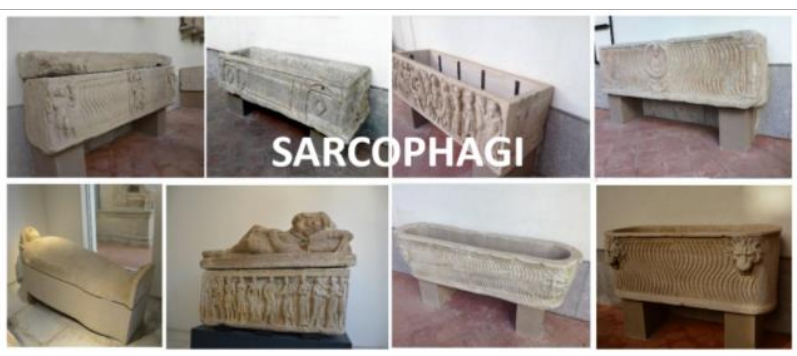

Figure 7 . The sarcophagi category: step 1

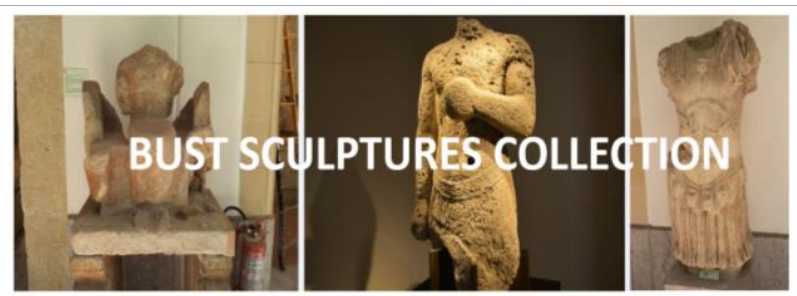

Figure 8 . The bust sculptures category: step 1

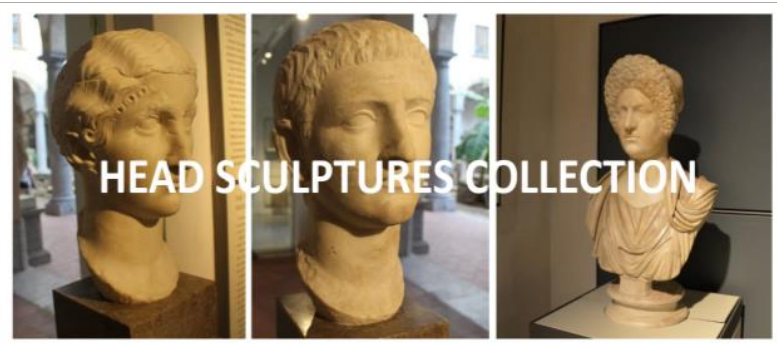

Figure 9. The head sculptures category: step 1

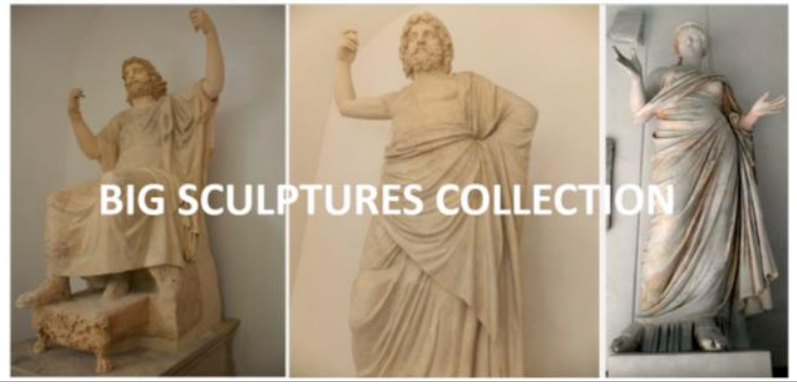

Figure 10. The big sculptures category: step 1

Then, I have programmed a number of groups depending on the number of types / objects to be photographed. In this way, the 
students were already best routed in order to achieve, each of them, from two to more datasets.

In the opening meeting of the event, there was a training lesson about the SfM techniques. (Fig. 11) This brief introduction lasted no more than half an hour, at the end of which students were able to make a data set independently. I gave them a fixed time beyond which they would have ended the dataset of an object to switch to a dataset of another object. (Fig. 12)

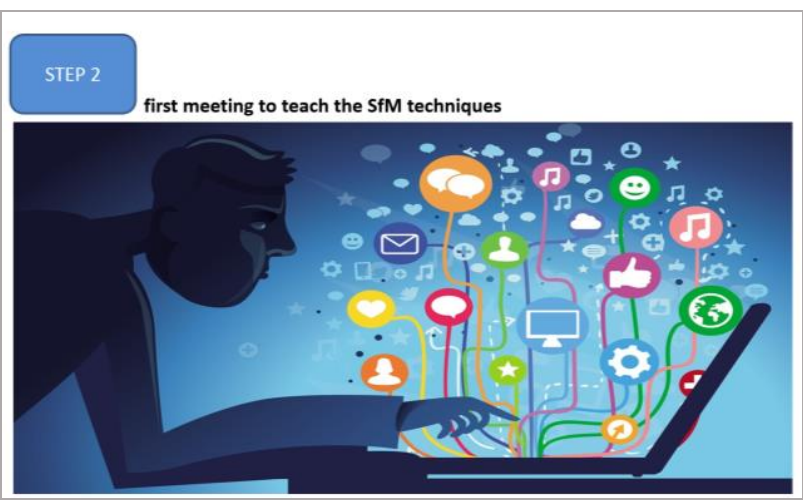

Figure 11. The tutorial lesson aimed at learning the SfM techniques: step 2

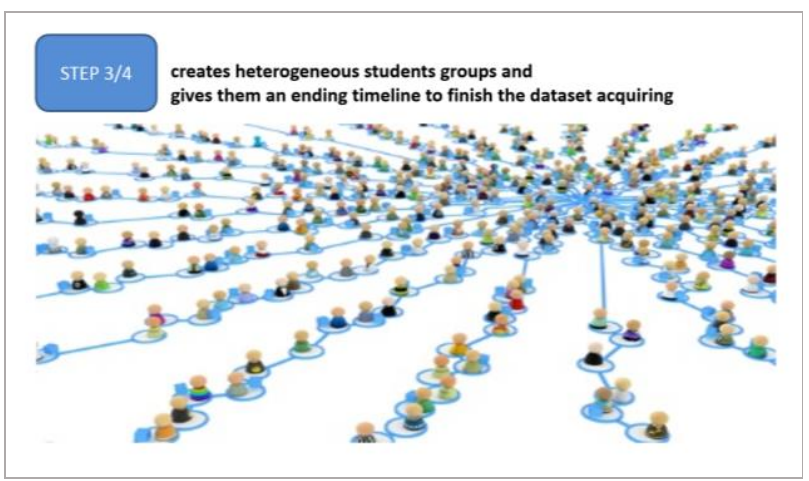

Figure 12. Students groups and timeline: steps 3 and 4

The students processed the data set on Photoscan and, at the end of each process, we upload all 3D models on a CD-rom of the outdoor museum collection.

The same procedure was repeated in 2016 on different objects. Below are some results. (Figg. 13, 14, 15, 16, 17, 18)

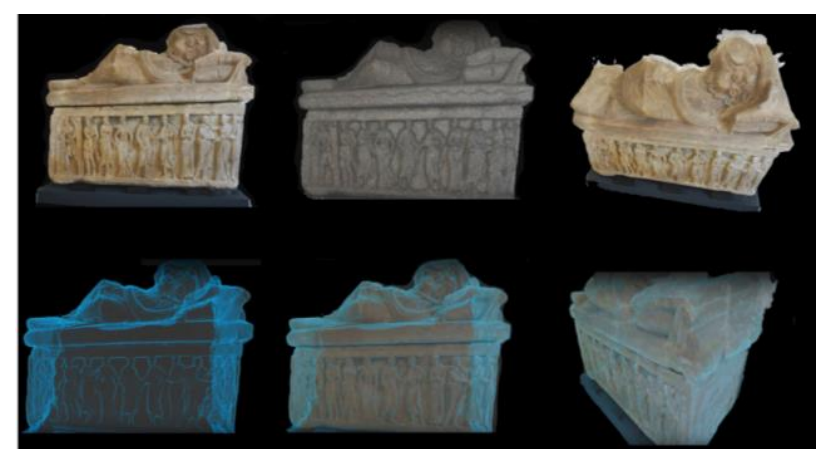

Figure 13. Sarcophagus 3D model

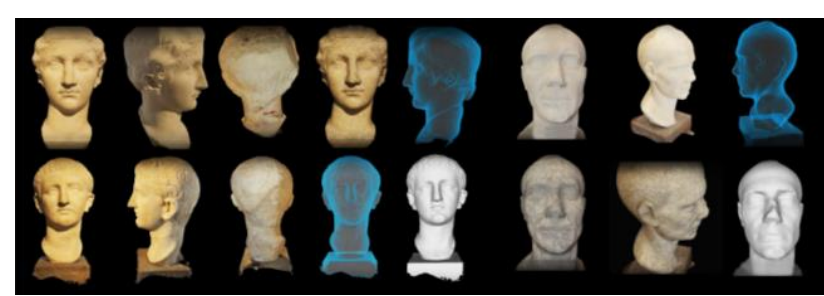

Figure 14. Head sculptures 3D models

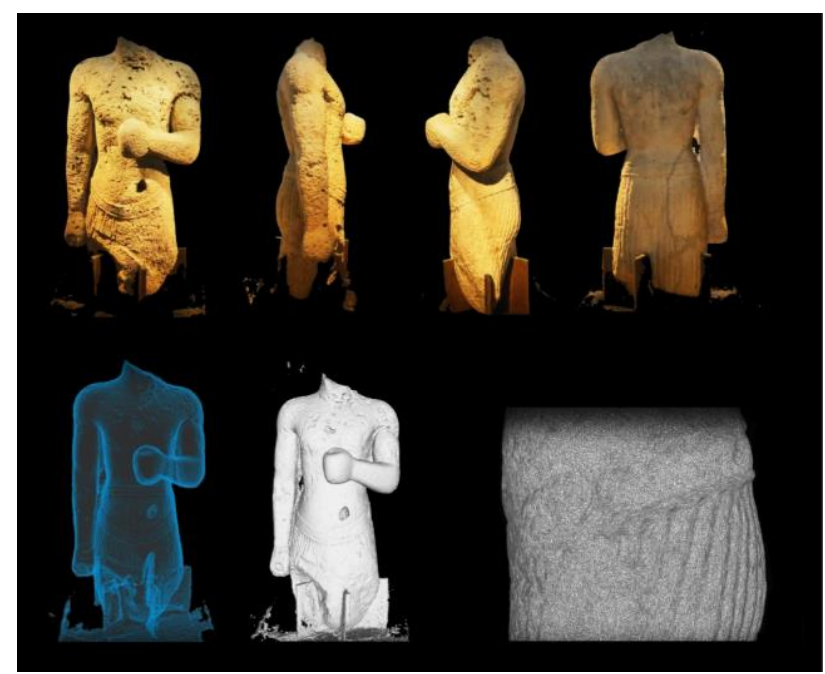

Figure 15. Bust Sculpture 3D model

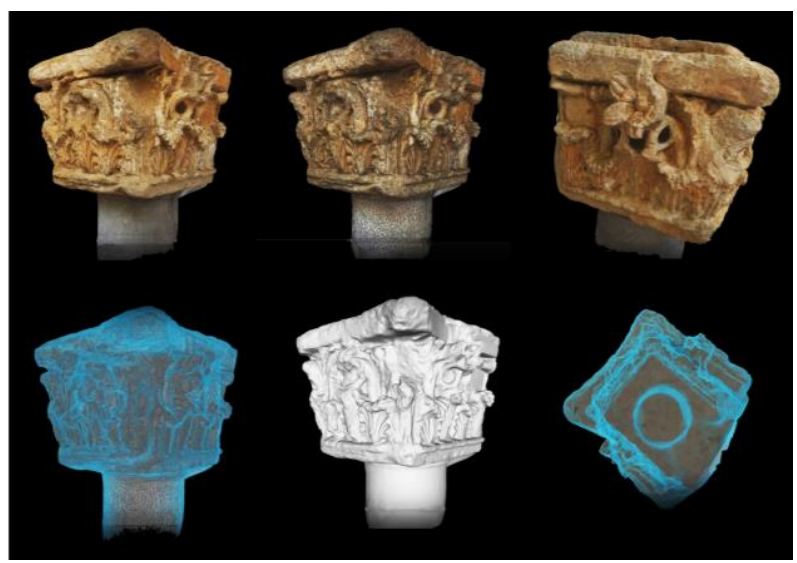

Figure 16. Capital 3D model

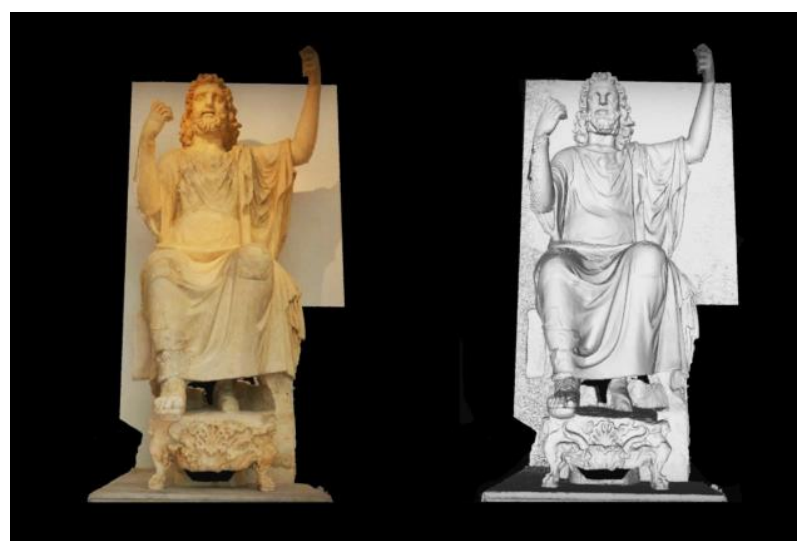

Figure 17. Zeus 3D model 


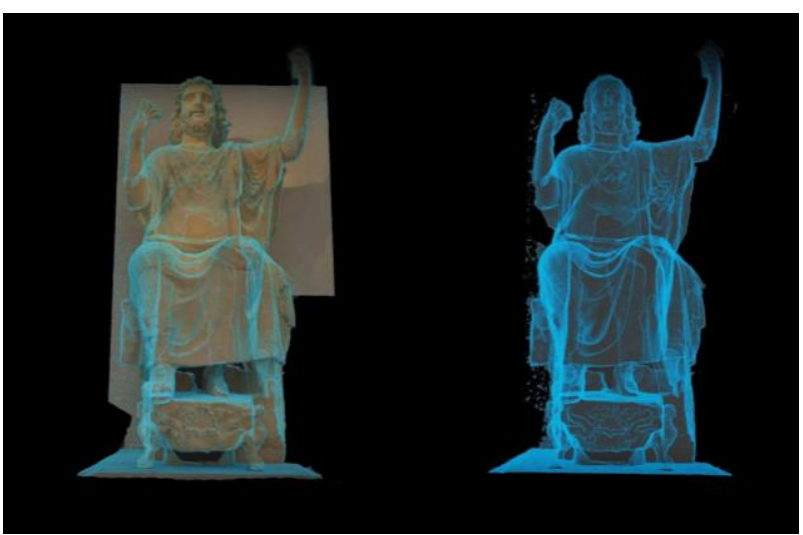

Figure 18. Zeus 3D model

\subsection{The workflow in 10 steps}

The high quality of 3D models and the possibility of having them in low cost mode, prompted the museum curator to collaborate on a project that would become a systematic solution in order to create the $3 \mathrm{D}$ models of the entire museum collection.

It is necessary to provide for two distinct actions in order to be able to give effect to the project.

On the one hand there are the tasks of the body and on the other the contribution of the museum visitor (crowdsourcing).

The project manager has the task:

of launching ideas and initiatives on social media;

to deal with the subdivision of museum collections according to their typology;

- make a two-years extended planning for the pieces of the collection to be captured;

to create a web platform where upload the 3D models;

to fit out a room to install workstation to upload the dataset and make the process;

to deal with make install a video tutorial on the using of SfM techniques;

to include awards for the best model so as to increase the competitiveness among the visitors and, therefore, the quality of the models. (Fig. 19)

On the other hand, the visitor must learn the SfM techniques from the video tutorial and then, must make the dataset and upload. He can decide to process the 3D model in a workstation at home and upload the model on the platform. (Fig. 20)

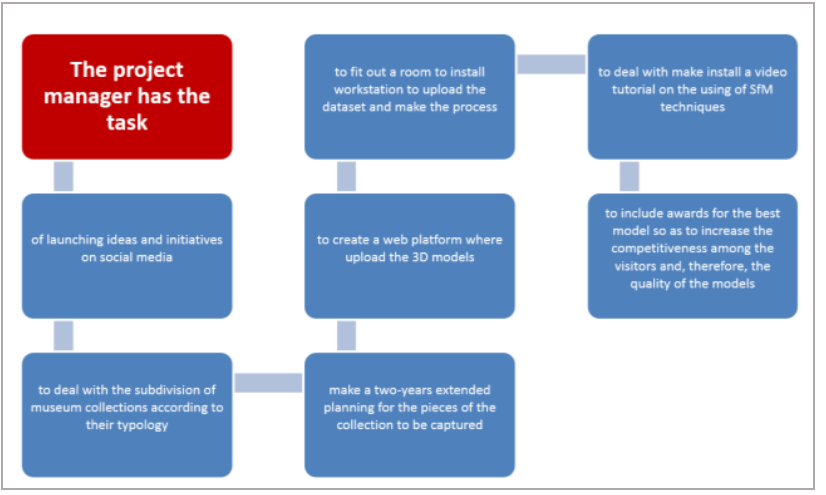

Figure 19. The big sculptures category

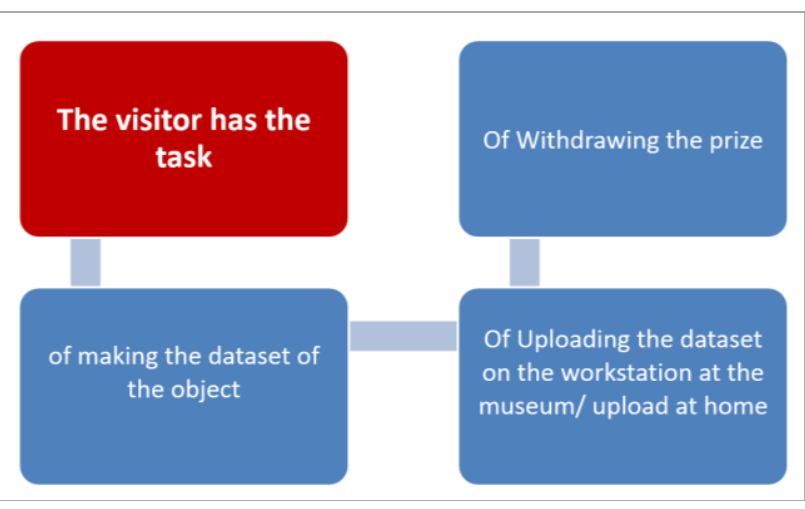

Figure 20. The big sculptures category

\subsection{The project manager and visitor task}

As shown in Figure 5, the role of the museum's curator is enormous. However, it is a one-off!

It is crucial on the project and each phase is delicate and paramount. There is no more important phase than another. Each phase has a fundamental role and needs to be considered as a crucial phase. The success of one determines that of the others.

The museum needs to attract the visitor with all possible means. He must be encouraged to participate in the survey campaign, driven by the ambition of becoming a co-creator of 3D models.

The museum can also think about awards for the best 3D model, or by the number of completed models.

On the other hand, the visitor who decides to participate in the initiative must find a friendly environment, working equipment, qualified personnel, effective video tutorials, a comfortable and inviting room designed for workstations. Everything, from the entrance to the exit museum, must naturally accompany the visitor who will give his contribution with enthusiasm.

If the first experience is positive, he will be driven to do it again and to involve friends and acquaintances to participate.

\section{CONCLUSIONS}

The experience, gained in just two days, allowed carrying out more than one hundred 3D models. The curators at the Salinas Museum in Palermo have shown a strong interest in collaborating on the project, which will enable the implementation of a crowdsourcing aimed at monitoring the collection. Actually, we are working on the automation of the SfM techniques in order to simplify the workflow and to allow to the visitor an easier process. (Fig. 21)

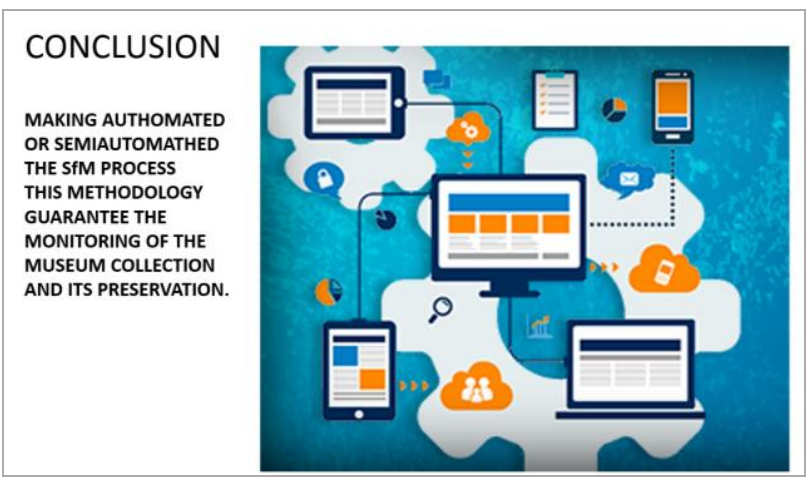

Figure 21. The automation of the SfM process will simplify the workflow 


\section{REFERENCES}

Alsadik, B. 2016. Crowdsource and web-published videos for 3D documentation of cultural heritage objects. In Journal of Cultural Heritage 25.4:899-903.

Biella, D., Sacher, D., Weyers, B., Luther, W., Baloian, N., Schreck, T. 2015. Crowdsourcing and Knowledge Co-creation in Virtual Museums. in Baloian, N., Zorian, Z., Taslakian, P., Shoukouryan, S., (eds) Collaboration and Technology, 21st International Conference, CRIWG 2015, Yerevan, Armenia, September 22-25, 2015, Proceedings. Lecture Notes in Computer Science 9334 , 1-18 (2015)

Bonacini, E., Marcucci, Todisco, F., 2014. \#DIGITALINVASIONS. A bottom-up crowd example of cultural value co-creation. In: proceedings of the First EAGLE International Conference 2014 on Information Technologies for Epigraphy and Digital Cultural Heritage, 2014, Paris, pp. 265- 284.

Guidi, G., Barsanti, Gonizzi, S., Micoli, L. L., Russo, M. 2015. Massive 3D digitization of museum contents, Built Heritage: Monitoring Conservation Management, pp 335-346 Springer International Publishing.

Howe, J. 2014. The Rise of Crowdsourcing. In Wired.Accessed June 1 , $2006 . \quad$ Available at https://www.wired.com/2006/06/crowds/

Kersten, T.P., Lindstaedt, M. 2012. Potential of Automatic 3D object reconstruction from multiple Images for applications. In Architecture, Cultural Heritage and Archaeology. International Journal of Heritage in the Digital Era1.3. pp. 399-420.

Kyriakaki, G., A.Doulamis,N. Doulamis,M. Ioannides, K. Makantasis, E.Protopapadakis, A.Hadjiprocopis, K. Wenzel, D.Fritsch, M.Klein, and G.Weinlinger. 2014. 4D Reconstruction of Tangible Cultural Heritage Objects from Web-Retrieved Images. International Journal of Heritage in the Digital Era3.2 (2014):431-452. doi:10.4399/97888548993917

Inzerillo, L., Santagati, C., 2016. Crowdsourcing cultural heritage: From 3D modeling to the engagement of young generations. In: 6th International Euro-Mediterranean Conference on Digital Heritage, EuroMed 2016; Part I. Lecture Notes In Computer Science, vol. 10058, p. 869-879, Cham: Springer International Publishing AG, ISBN: 978-3-319-484969, ISSN: 0302-9743, doi: 10.1007/978-3-319-48496-9_70 Nicosia, Cyprus, Greece, 31 October 2016 through 5 November

Mikhail, E. M., Bethel, J. S., \& McGlone, J. C. 2001. Introduction to modern photogrammetry. New York: Chichester: Wiley.

Moussa, W.,M. Abdel-Wahab, and D. Fritsch. 2012. An Automatic Procedure for Combining Digital Images and Laser Scanner Data. In The International Archives of the Photogrammetry, Remote Sensing and Spatial Information Sciences. vol. XXXIXpartB5 (2012):229-234.

Oomen, J., Lora, A. 2011. Crowdsourcing in the cultural heritage domain: opportunities and challenges. In Proceedings of the 5th International Conference on Communities and Technologies. 138-149.
Smith, M. W., Carrivick, J. L., \& Quincey, D. J. 2015. Structure from motion photogrammetry in physical geography. Progress in Physical Geography, 309133315615805.

Stathopoilou, E.K.,Georgopoulos, A., Panagiotopoulis, G., Kaliampakos, D., 2015. Crowdsourcing lost cultural heritage. In ISPR Annals of Photogrammetry Remote Sens. Spat. Inf. Sci. II5/W3, 295-300.

Verhoeven, G. 2011. Taking computer vision aloft archaeological three-dimensional reconstructions from aerial photographs with photoscan. Archaeological Prospection, 18(1), 67-73. http://doi.org/10.1002/arp.399

Vincent, M. L., Coughenour,C., Remondino, F., Gutierrez, M.F., Bendicho, L., Menchero, Manuel, V., Frtisch, V. 2015. Crowd-sourcing the 3D digital reconstructions of lost cultural heritage. In: Digital Heritage. 171-172.

Westoby, M. J., Brasington, J., Glasser, N. F., Hambrey, M. J., \& Reynolds, J. M. 2012. "Structure-from-Motion" photogrammetry: A low-cost, effective tool for geoscience applications. Geomorphology, 179, 300-314. http://doi.org/10.1016/j.geomorph.2012.08.021 